\title{
Política pública e educação ambiental: aspectos conceituais e ideológicos de participação, democracia e cidadania em Sergipe
}

\author{
Public policy and environmental education: conceptual and ideological aspects \\ of participation, democracy and citizenship in Sergipe \\ Política pública y educación ambiental: aspectos conceptuales e ideológicos \\ de participación, democracia y ciudadanía en Sergipe
}

ALINE LIMA DE OLIVEIRA NEPOMUCENO MARIA INÊZZ OLIVEIRA ARAUJO

\begin{abstract}
Resumo: Esta pesquisa visa compreender a Política Estadual de EA de Sergipe quanto as concepções de participação, democracia e cidadania. Em síntese, os resultados dos dados produzidos revelaram que existem tendências para a não escolarização da Lei n. ${ }^{\circ}$ 6.882/10, pois há inaplicabilidade de alguns artigos dessa política na prática pedagógica; há o reforço da prática educativa socioambiental fragmentada e conservadora, potencializada em um currículo tecnicista, baseado em conteúdos; há ainda o abafamento das particularidades das escolas públicas sergipanas, homogeneizando suas práticas educativas.
\end{abstract}

Palavras-chave: Educação Ambiental Crítica. Emancipação. Políticas Públicas.

\begin{abstract}
This research aims to understand the state policy of EA of Sergipe as the conceptions of participation, democracy, and citizenship. In summary, the results of the data produced revealed that there are trends for the non-schooling of Law 6.882/10, as there are inapplicability of some articles of this policy in the pedagogical practice; there is the reinforcement of the fragmented and conservative socio-environmental educative practice, potentiated in a technicist curriculum, based on content; there is also the muffling of the particularities of the public schools of Sergipe, homogenizing their educational practices.
\end{abstract}

Keywords: Critical environmental education. Emancipation. Public policy.

Resumen: Esta investigación tiene como objetivo comprender la Política de Estado de EA de Sergipe como las concepciones de participación, democracia y ciudadanía. En resumen, los resultados de los datos producidos revelaron que existen tendencias para la no escolarización de la ley 6.882/10, pues hay inaplicabilidad de algunos artículos de esta política en la práctica pedagógica; hay el refuerzo de la práctica educativa socioambiental fragmentada y conservadora, potenciada en un currículo tecnicista, basado en contenidos; hay todavía el silenciamiento de las particularidades de las escuelas públicas de Sergipe, homogeneizando sus prácticas educativas.

Palabras clave: Educación Ambiental Crítica. Emancipación. Políticas Públicas.

RBPAE - v. 35, n. 3, p. 941 - 960, set./dez. 2019 • 941 


\section{PRESSUPOSTOS METODOLÓGICOS E EPISTEMOLÓGICOS PARA A CONSTRUÇÃO DE POLÍTICAS PÚBLICAS}

A crise socioambiental que envolve a todos os seres humanos tem ganhado proporções planetárias. $\mathrm{O}$ atual estágio de desenvolvimento do modo de produção capitalista atingiu, nesse sentido, patamares de destruição ambiental não experimentados em nenhuma outra fase da história da humanidade. Nessa direção, a Educação Ambiental (EA) passou a ser apresentada como uma importante estratégia para a formação de indivíduos partícipes na construção de uma sociedade sustentável, socialmente justa e ecologicamente equilibrada.

Nesse ínterim, o histórico de criação de políticas públicas de EA em âmbito federal no Brasil teve início em 1973 com a criação da Secretaria Especial de Meio Ambiente (Sema), cuja atribuição, dentre outras, era “o esclarecimento e a educação do povo brasileiro para o uso adequado dos recursos naturais, tendo em vista a conservação do meio ambiente" (BRASIL, 2005, p. 22).

Apenas em 1981, a EA apareceu pela primeira vez em um marco legal federal, inserida como um princípio da Política Nacional do Meio Ambiente (BRASIL, 1981). Posteriormente, em 1988, sua importância foi reforçada com o destaque da Constituição Federal, artigo n. ${ }^{\circ}$ 225, como uma forma de se assegurar o direito de todos ao meio ambiente ecologicamente equilibrado e também de defesa e preservação ambiental para as gerações presentes e futuras (BRASIL, 1988).

$\mathrm{Na}$ década de 1990, a EA ganhou maior espaço nas discussões em diversos setores da sociedade - inclusive nas instituições de ensino -, momento este ocasionado principalmente pela Conferência das Nações Unidas para o Meio Ambiente e Desenvolvimento, conhecida como Rio-92, ocorrida no Rio de Janeiro. Com as influências anteriores e posteriores à Eco-92, a EA passou a se fazer mais presente em diferentes instâncias governamentais, como no Ministério da Educação (MEDINA, 1997) e no nascente Ministério do Meio Ambiente. Em 1994, apoiando esse fortalecimento, o governo federal criou o Programa Nacional de Educação Ambiental, documento que, ao longo de sua história, estará sujeito a constantes revisões públicas (BRASIL, 2005).

Em seguida, direcionando a EA à formação humana e cidadã, foi criada, em 1999, a Política Nacional de Educação Ambiental, Lei n. ${ }^{\circ}$ 9795/99 (BRASIL, 1999), que, além de muitos outros encaminhamentos, institui a EA como obrigatória em todos os níveis de ensino formal. 
Ademais, recentemente, marcando as primeiras décadas do séc. XXI, realizou-se também no Rio de Janeiro mais uma Conferência das Nações Unidas sobre Desenvolvimento Sustentável (Rio +20 ), cujo objetivo principal foi discutir a renovação do compromisso político com o desenvolvimento sustentável ${ }^{1}$.

Nesse sentido, em 2010, foi instituída, em Sergipe, a Política Estadual de Educação Ambiental, Lei n. ${ }^{\circ}$ 6882/10 (SERGIPE, 2010), que dispõe sobre a Educação Ambiental e seus princípios, objetivos e campos de atuação, visando à garantia do envolvimento ativo e permanente da comunidade escolar na defesa da qualidade socioambiental do território onde está inserida.

Nesse cenário, a EA surge como como um campo a ser implementado, tendo em vista a crescente degradação dos recursos naturais, que vitima todo o planeta. Assim, como contribuição desses e demais encontros, vêm sendo promovidos questionamentos sobre as formas de ocupação e exploração que o ser humano tem destinado ao meio ambiente natural e, consequentemente, ao ambiente social e cultural. Nasce, dessa forma, a preocupação de dotar a EA de sólidos argumentos que possibilitem uma maior e melhor compreensão das questões ambientais e dos desafios políticos, culturais, sociais, econômicos e ecológicos que envolvem a todos.

Esses eventos, ora apresentando avanços ora recuos, demonstram as tentativas de criação de estratégias em diferentes escalas geográficas - da local à global e vice-versa - com vistas à construção de uma sociedade mais equilibrada e harmoniosa. No entanto, tais tentativas ainda esbarram na manutenção de sociedades classistas e neoliberais, cujos interesses que imperam pertencem a uma minoria.

Com efeito, decorrente das diferentes visões de mundo que constituíram a EA, ao longo da história, e da pluralidade de perspectivas pedagógicas inerentes à sua prática, muitas são as possibilidades de entendimento dos conceitos associados à dimensão ambiental. Contudo, chamam a atenção as ações em EA que ainda hoje se apresentam fragilizadas, mesmo com a crescente difusão da EA, sobretudo no processo educativo (GUIMARÃES, 2004). Na maior parte das escolas, a EA geralmente é trabalhada de forma fragmentada e descontextualizada, o que caracteriza as práticas conservadoras, como demonstram os resultados obtidos na pesquisa $O$ que fazem as escolas que dizem que fazem educação ambiental?, elaborada pelo Ministério da Educação (MEC) e iniciada em 2005 (TRAJBER; MENDONÇA,

"Atualmente, o conceito de desenvolvimento sustentável indica claramente o tratamento dado à natureza como um recurso destinado aos objetivos de mercado, cujo acesso é priorizado a parcelas da sociedade que detêm o controle do capital. Este paradigma mantém o padrão de desenvolvimento que produz desigualdades na distribuição e no acesso a esses recursos, produzindo a pobreza e a falta de identidade cidadã" (SORRENTINO et al, 2005, p. 289). 
2006). Em razão dessas práticas, a inserção da EA tem sido feita basicamente por três caminhos: projetos, disciplinas especiais e inserção da temática ambiental nas disciplinas.

Por isso, é importante investigar os discursos presentes no campo da EA, particularmente materializados nesta pesquisa, nos documentos oficiais que definem suas diretrizes e suas políticas públicas, em especial, a de Sergipe, instituída pela Lei n. ${ }^{\circ}$ 6882/10, que concretizou a Política Estadual de Educação Ambiental. Assim, nesta pesquisa, buscam-se respostas para alguns desafios enfrentados na implementação da EA, especificamente no tocante à Lei n. ${ }^{\circ}$ 6882/10 para a educação formal, analisando seus objetivos, suas justificativas, suas implicações e suas consequências políticas, sociais e educacionais para a educação formal em Sergipe.

Diante dessas primeiras reflexões o interesse aqui é compreender criticamente o discurso da Lei n. ${ }^{\circ}$ 6882/10 e suas possíveis repercussões nas escolas do estado sergipano. Isto se justifica em razão de um cenário de superficialidade de inúmeros debates políticos, o que acaba conduzindo ou a acusações e críticas pouco fundamentadas teórica e epistemologicamente, ou a consensos extremamente rasos e frágeis.

Destarte, o tema, cujo foco está em entender os diferentes sentidos em disputa que têm sido socio-historicamente mobilizados e imprimidos nas políticas públicas, sobretudo no campo da EA para o contexto escolar na tentativa de compreender os processos que envolvem a EA com base em estudos que vislumbram a EA da/na/para a escola, concebendo-a como mais um importante espaço de formação humana, emancipação e de enfrentamento dos problemas socioambientais. Nesse sentido, a EA pode ser concebida como proposta pedagógica e política, estratégia fundamental para refletir e direcionar ações e sugestões políticas que visem à superação de discursos e práticas homogêneas e de consensos superficializantes em torno da questão socioambiental.

Essa escolha pode ser também justificada, em primeiro lugar, por ser esta a principal política pública estadual de EA em Sergipe, assim como é, também, diretriz para a elaboração de ações no escopo da EA em escolas estaduais sergipanas; em segundo lugar, por ser este o Estado em que a pesquisadora reside, local de suas primeiras, atuais e futuras pesquisas.

A finalidade deste trabalho é analisar a Política Pública Estadual de EA de Sergipe (PEEA), com base no texto consolidado em 2010 no que tange as concepções de cidadania, participação e democracia da referida lei, especialmente, o capítulo que trata da Educação Formal. Tais reflexões foram desenvolvidas, destacando, em certos momentos, algumas passagens da política analisada, consideradas relevantes para a apreensão das concepções supracitadas. Por meio 
dessas primeiras análises, busca-se uma aproximação entre a teoria e a prática da política em questão junto ao processo educativo nas escolas do Estado de Sergipe para a potencialização da dimensão socioambiental como ação emancipatória, coletiva e questionadora.

Em virtude do objetivo desta pesquisa, a abordagem metodológica aqui adotada tem natureza qualitativa para a investigação e para o relato analítico de experiências realizadas (MINAYO, 1994). A pesquisa documental se resumiu a buscas no site $^{2}$ da Secretaria de Estado do Meio Ambiente e Recursos Hídricos (SEMARH) do texto original da Lei n. ${ }^{\circ}$ 6882/10. Todos os documentos coletados, arquivos da SEED ou das escolas estaduais e da SEMARH, estão disponíveis publicamente na internet.

As informações coletadas foram analisadas à luz do referencial teórico que abarca a perspectiva da EA crítica como ato político de transformação da realidade, superando a visão hegemônica e reduzida da realidade e entendendo a prática pedagógica como contextualizada e emancipatória. Essas escolhas se aproximaram da Análise Textual Discursiva (ATD) (MORAES; GALIAZZI, 2006; MORAES, 2003) como metodologia de análise dos dados produzidos nas entrevistas e no texto da política em questão, capaz de subsidiar a análise crítica da realidade investigada.

Para esta pesquisa, baseada numa dinâmica aproximada à ATD, foram desenhados eixos temáticos a priori, como linhas de investigação delimitadas pelo objeto de pesquisa e como categorias/tendências consubstanciadas no referencial teórico utilizado. Lançar mão de estudos e análises críticas da principal política pública do Estado de Sergipe acerca da EA é mais uma tentativa de entender como esse processo socio-histórico formativo vem se instaurando, em especial nas escolas estaduais do citado estado, como pretende este estudo. Dessa maneira, são delineadas, nesta pesquisa, as principais categorias analíticas:

a) Cidadania ecológica: implica a clara noção de direitos, deveres e responsabilidades cívicas na busca de uma sociedade sustentável, o que envolve o plano ideocultural e o político-econômico; em síntese, trata-se da cidadania plena e da ecocidadania ou, melhor dizendo, de uma ecocidadania plena e de fato (LOUREIRO, 2008).

b) Participação e democracia: demanda a atuação democratizante e de valorização da participação do indivíduo em movimentos coletivos na definição das políticas públicas, tendo em mente o fortalecimento da cidadania, seguindo as orientações mais gerais de Giddens (2001) acerca da democracia dialógica e de Held (1994) acerca da democracia cosmopolita e entendendo a participação 
com base material assegurada, como eixo essencial para a democratização e para a concretização de um modelo de desenvolvimento alternativo (LOUREIRO, 2008).

Nas categorias citadas, são abordados conscientemente assuntos recorrentes no interior da EA, das políticas públicas e da Educação Formal, sem pretender esgotar a discussão, numa área em que o enfoque interdisciplinar e crítico é extremamente relevante, para não dizer indispensável. Além disso, com esta pesquisa, é possível contribuir com o campo de discussão que desvela apropriações e ressignificações de importantes categorias referenciadas por uma práxis pedagógica contra-hegemônica, capaz de intervir na realidade e contribuir com o enfrentamento da crise socioambiental da atualidade.

\section{CONCEPÇÕES DE CIDADANIA}

A concepção clássica de cidadania é cumulativa e passiva, não atendendo à demanda de inclusão na sociedade global e de construção de uma responsabilidade ativa. Para Marshall (1967), o desenvolvimento da cidadania levava a um efeito integrador da sociedade, na medida em que o Estado concedia os direitos acordados entre as classes. Assim, o autor se utiliza de um modelo de cidadania segundo o qual a garantia dos direitos por um Estado forte era a garantia de uma vida digna, já que seu modelo se pautava no Welfare State.

Entretanto, infelizmente, o termo cidadania, nos últimos anos, vem sendo vulgarizado com sentidos muito diferentes. Torna-se um termo "[...] perigosamente consensual, um envelope vazio, no qual podem tanto caber sonhos de uma sociedade de iguais, uma sociedade de direitos e deveres, quanto uma sociedade dividida por interesses antagônicos" (GADOTTTI, 2008, p. 66). Ou seja, há o risco de amenizar o caráter pleno e crítico da cidadania a uma noção neoliberal do termo. Nesse sentido, enfatiza Demo (2009, p. 70):

O conceito de cidadania possui laivos conservadores históricos, desde a postura grega, que preservava como cidadãos somente a um pequeno grupo de elite, a postura liberal, que admite como cidadãos os que possuem capital e poder, até a postura da cidadania consentida, tutelada pelo Estado e seus donos. Esta observação já é suficiente para caracterizar a importância da forma organizada, que significa entender a cidadania a partir dos interessados, dos desiguais, dos excluídos.

Nos discursos sobre cidadania, há uma tendência em considerá-la como ter direito a ter direitos (civis, sociais e políticos), negligenciando o fato de que os próprios indivíduos podem ser sujeitos sociais ativos, agentes da existência de seus direitos e construtores de sua própria história, em suma, agentes políticos 
(OLIVEIRA, 2012). “A cidadania não é um 'estado de espírito', uma 'consciência de direitos' ou 'um direito adquirido'. Ela é a construção - 'construtivista' ou não - de uma ética política de corresponsabilidade de presença-e-partilha de construção do cotidiano" (BRANDÃO, 2002, p. 132). Para Loureiro (2011, p. 77), "os direitos não são dados, mas conquistados; a garantia formal e legal não implica que a igualdade seja praticada; e o que foi entendido como válido hoje poderá não mais o ser e vice-versa".

Com tudo isso, torna-se relevante identificar as apropriações que as políticas públicas fazem do conceito de cidadania (neste caso, a PEEA) e analisar como essa perspectiva é associada à EA nesse discurso político participativo. O termo cidadania desponta no texto da política analisada em cinco momentos, destacados nos fragmentos da referida lei.

Art. $2^{\circ}$ Os pilares desta política estão consubstanciados nos componentes Educação Ambiental e Sustentabilidade, que viabilizaram ética e formação de cidadania, voltados para a inclusão social. (SERGIPE, 2010, p. 1, grifo nosso)

Art. $7^{\circ}$ São objetivos básicos da Educação Ambiental:

$[\cdots]$

IV - o incentivo à participação individual e coletiva, permanente e responsável, na conservação e preservação do equilíbrio do meio ambiente, entendendose a defesa da qualidade ambiental como um valor inseparável do exercício da cidadania.

$[\cdots]$

VII - o fortalecimento da cidadania, autodeterminação dos povos e solidariedade como fundamentos para o futuro da humanidade. (SERGIPE, 2010, p. 4-5, grifo nosso)

Art. $9^{\circ}$ A Política Estadual de Educação Ambiental em consonância com a Política Nacional de Educação Ambiental tem como objetivos:

$[\cdots]$

$\mathrm{V}$ - promover a sensibilização despertando a consciência dos indivíduos para a gestão compartilhada e cidadã do meio ambiente;

$[\ldots]$

XIV - incentivar como prática de Educação Ambiental a elaboração e execução de projetos socioeducativos que trabalham com múltiplos espaços educativos, valorizando as possibilidades científicas artísticas, produtivas e culturais, objetivando a formação da cidadania na perspectiva da Educação Integral. (SERGIPE, 2010, p. 6-8, grifo nosso)

Diante do exposto, na PEEA, a cidadania está relacionada, primeiro (Art. $2^{\circ}$ ), ao processo de inclusão social; segundo (Art. $7^{\circ}$, inciso IV), ao exercício de responsabilidade individual e/ou coletiva; terceiro (Art. $7^{\circ}$, inciso VII), ao ato de solidariedade; quarto, à forma de gestão compartilhada; e, por último (Art. $9^{\circ}$, incisos V e XIV), ao processo formativo na perspectiva da Educação Integral. 
Analisando o documento, mesmo com as poucas inferências encontradas sobre o sentido de cidadania, é louvável a vinculação do fazer ambiental ao exercício da cidadania em uma leitura para a inclusão social, reconhecendo que se vive a concretude de uma sociedade estratificada. Nessa perspectiva, o exercício da cidadania plena, como prática humana e social intencional, "pressupõe a liberdade, a autonomia e a responsabilidade” (RODRIGUES, 2001, p. 238).

Em contradição, há um deslocamento de cidadania, solidariedade $e$ responsabilidade que obscurece sua dimensão política e corrói as referências à responsabilidade pública e ao interesse público, construídas com tanta dificuldade pelas lutas democratizantes do passado recente. A distribuição de serviços e benefícios sociais passa cada vez mais a ocupar o lugar dos direitos e da cidadania, obstruindo não só a demanda por direitos, mas, mais grave, obstando a própria formulação dos direitos e da cidadania e a enunciação da questão pública (DAGNINO, 2004).

No que tange à cidadania como exercício de gestão compartilhada, a PEEA faz referência ao processo educativo, cuja base é o PNE, aprovado e sancionado em janeiro de 2001 pela Lei n. 10.172 (BRASIL, 2001) e pela LDB, Lei n. ${ }^{\circ} 9.394$ (BRASIL, 1996). Assim, os processos de gestão educacional podem promover a implementação de políticas públicas específicas, como é o caso da Lei n. ${ }^{\circ}$ 6.882/10. Nesse sentido, o exercício pleno da cidadania deve se articular à formação crítica e emancipatória para "[...] a prática da reivindicação, da apropriação de espaços, da pugna para fazer valer os direitos dos cidadãos" (CERQUIER-MANZINI, 2010, p. 10). A universalização da cidadania plena não se limita à garantia de direitos, de leis e de crescimento econômico, mas sim a:

Condições objetivas e materiais justas, que assegurem a superação de padrões de Estado ditatoriais, assistencialistas e paternalistas, que inibem a participação e a ruptura com os modelos societários que criam uma tradição cultural de submissão à lógica econômica de mercado privatista (alienante) estabelecida. (LOUREIRO, 2011, p. 78)

Torna-se necessário, portanto, repensar o sentido de cidadania que tem sido praticado e buscar a conversão da ideia de tutela assistida para uma perspectiva verdadeiramente democrática, entendida aqui não apenas no sentido de ter direito a ter direitos, mas sim no sentido da emancipação humana. Em face do exposto, é preciso entender que não bastam leis, documentos ou princípios aprovados em grandes conferências, já que estas, muitas vezes, podem legitimar o caráter político neoliberal. $\mathrm{Na}$ verdade, são imprescindíveis discussões apropriadas na 
luta política dos sujeitos individuais e coletivos, as quais conformam o campo da EA transformado em práticas sociais e políticas efetivas realmente assumidas pelos órgãos gestores e pelos agentes da educação (OLIVEIRA, 2012).

Com efeito, a Educação Integral pode ser uma ferramenta importante nesse processo, desde que seja realizada com a devida infraestrutura e que a escola não perca a sua função pedagógica na construção da cidadania, buscando questionar o modelo hegemonizante vigente.

Por tudo isso, vive-se um contexto extremamente desafiador. É, portanto, preciso retomar, no horizonte imediato, as políticas públicas como políticas universais democratizantes, de direito de cidadania, de educação, de participação, tal como reza a Constituição. E, com isso, buscar o exercício da cidadania na problematização e na transformação das condições materiais de vida e na ressignificação da inserção individual e social no ambiente (GUIMARÃES, 2000).

O exercício da cidadania ambientalista vai muito além da preocupação em solucionar apenas problemas ambientais. O exercício da cidadania socioambiental crítica, contextualizada e relacional tem um caráter pedagógico. De fato, “[...] a única concretização efetiva da emancipação consiste em que aquelas poucas pessoas interessadas nessa direção orientem toda a sua energia para que a educação seja uma educação para a contradição e para a resistência" (ADORNO, 2006, p. 183).

\section{CONCEPÇÕES DE PARTICIPAÇÃO E DEMOCRACIA}

Nos últimos anos, a participação - associada à ideia de democracia ou de democratização, em um enfoque de processo - tem sido muito festejada e exigida ou encarada como uma ação quase "fora de moda" que, afinal, não se mostrou muito útil na construção das "democracias de baixa intensidade", as quais, assentadas na força e no poder de exclusão do mercado, geraram atitudes de apatia e passividade (SANTOS, 2005, p. 160).

Nessa perspectiva, discorrer sobre a participação é crucial para a consolidação da verdadeira cidadania, pois esta é o centro da aprendizagem política e é por meio dela que se vincula a educação à cidadania e se concretiza a cidadania em suas múltiplas dimensões (LOUREIRO, 2004). Por intermédio da participação, o indivíduo desenvolve a capacidade de ser senhor de si mesmo. Entretanto, 
O risco - real - que se percebe é que a participação da sociedade civil nas instâncias decisórias, defendida pelas forças que sustentam o projeto participativo democratizante como um mecanismo de aprofundamento democrático e de redução da exclusão, possa acabar servindo aos objetivos do projeto que lhe é antagônico. (DAGNINO, 2004, p. 97)

Reinventar a participação, no enfoque de construção contra-hegemônica, pressupõe entendê-la como um processo complexo e contraditório entre a sociedade civil, o Estado e o mercado, cujos papéis são redefinidos por meio do fortalecimento dessa sociedade civil na atuação organizada de indivíduos, grupos e associações. É preciso, “[...] sobretudo, evitar a participação pela participação. Miséria participada não interessa a ninguém” (DEMO, 2009, p. 67).

A participação precisa se consolidar no sentido de ajudar a perceber as estruturas dominantes de poder de que estão impregnados os diferentes aspectos da vida (MÉSZÁROS, 2002). Este é um exercício que pressupõe que revele a realidade e ajude a construir visões lúcidas com base em caminhos alternativos. Nesse sentido, atitudes participativas democráticas potencializam a capacidade de atuação/transformação do sujeito no processo social, direcionando essas ações para a construção de um novo modelo de sociedade, pautado em uma nova ética nas relações entre os seres humanos e, consequentemente, entre eles e a natureza (GUIMARÃES, 2000).

Todavia, hoje, um dos grandes problemas da participação e, logo, da democracia é que se vive uma sociedade heterônoma. Em diversos momentos, as pessoas se identificam com isso e acabam por, sem saída, submeter-se às regras, sentindo prazer e querendo fazer de tudo para, ao menos, se manter nesse jogo. Assim, mesmo sendo a sociedade emancipada, corre-se o risco de torná-la, a qualquer momento, não emancipada.

Como é um dos objetivos deste estudo, a PEEA também é analisada quanto à perspectiva participativa e democrática. Nesse caminho de mapear as concepções de participação, foi possível identificar, predominantemente, na política pública supracitada, a participação como sinônimo de composição, de fazer parte, como comprovam alguns trechos. 
Art. $2^{\circ}$. Parágrafo único. As instituições públicas, empresas privadas e organizações não governamentais que estejam de alguma maneira envolvidas com a questão ambiental no âmbito do Estado de Sergipe, serão convidadas pelo órgão gestor a participarem, semestralmente, de fóruns permanentes para compartilharem discussões, atualizações e avaliações de propostas e ações com a temática Educação Ambiental. (SERGIPE, 2010, p. 1, grifo nosso)

Art. $7^{\circ}$. São objetivos básicos da Educação Ambiental:

$[\ldots]$

IV - o incentivo à participação individual e coletiva, permanente e responsável, na conservação e preservação do equilíbrio do meio ambiente, entendendose a defesa da qualidade ambiental como um valor inseparável do exercício da cidadania. (SERGIPE, 2010, p. 4, grifo nosso)

Art. $11^{\circ}$. Entende-se por Educação Ambiental Não-Formal, as ações e práticas educativas voltadas à sensibilização da coletividade sobre as questões ambientais e a sua organização e participação na defesa da qualidade do meio ambiente, tendo como diretrizes:

$[\cdots]$

XI - dinamizar, apoiar e promover a Rede de Educação Ambiental de Sergipe e outras redes, visando uma maior participação e democratização de informações no processo construtivo e educativo;

$[\cdots]$

XIV - implementar a Educação Ambiental na política agrícola valorizando a participação da família do campo, estimulando a prática da agropecuária sustentável a exemplo da agroecologia, agroflorestal, agrossilvicultura, permacultura, agricultura orgânica, dentre outros. (SERGIPE, 2010, p. 9-11, grifo nosso)

As cooptações desse tipo de sentido atribuído à participação podem ocorrer quando o objetivo é a reunião de todos em prol de algo, em favor de alguma causa posta como um interesse comum, que a todos uniformiza, como uma incubadora de consensos absolutos que silencia conflitos. No entanto, esse senso de coletividade acaba por homogeneizar os sujeitos sociais, igualandoos, subtraindo suas desigualdades, sob uma lógica neoliberal de participação individualizada e amorfa.

Participar, nesse caso, é o mesmo que consentir, conviver, reforçar, retroalimentar e legitimar a lógica de acumulação do capital, em um sentido de "domesticação da participação popular, mediante políticas restritivas de tal participação, por sua vez baseadas numa concepção individualista da sociedade civil dominada pelas organizações empresariais" (SANTOS, 2005, p. 12). Ademais, mostra-se uma participação deslocada de um sentido contra-hegemônico, pois reafirma o regime de relações de poder, de exclusão, e silencia ações participativas políticas e cidadãs. 
Em vista disso, para Backer (1991), existe uma multiplicidade de formas coletivas de participação da sociedade, dentre as quais o direito de ser consultada, antes de uma decisão do poder público; o direito de negociar, mediar e participar da decisão propriamente dita, transcendendo, assim, a perspectiva puramente individualista de participação como contribuição em pequenas questões cotidianas, como participar reduzindo o consumo conspícuo, eliminando o desperdício, reciclando o lixo, mantendo o veículo bem regulado e consumindo verde, entre outras coisas.

Ainda nessa direção, existe uma participação individualista, uma "participação solidária" (DAGNINO, 2004, p. 102), que delega responsabilidade social aos indivíduos e às empresas. Para tanto, o Estado negligencia seu papel social, econômico e cultural e transfere suas responsabilidades para a sociedade e, principalmente, para o setor privado. Nesse momento, consagra-se o Estado Mínimo, segundo Cunha (2009), e o comunitarismo, como solução para as desigualdades sociais: "O princípio básico aqui parece ser a adoção de uma perspectiva privatista e individualista, capaz de substituir e redefinir o significado coletivo da participação social" (DAGNINO, 2004, p. 102).

Essa concepção participativa está atrelada ao sentido hegemônico de democracia, que se sustenta na propalada contradição entre mobilização e institucionalização, na ética individualista e moralista de responsabilização e culpabilização, na valorização da apatia política, na concentração do debate democrático no período meramente eleitoral, na abordagem do pluralismo simplesmente como diferenciação partidária ou na disputa de projetos em uma eleição e, por fim, na restrição do entendimento de participação política (SANTOS, 2005; AVRITZER, 2002).

Diante do exposto, Oliveira (2012, p. 86) classifica participação em dois sentidos:

Que são processos participativos e outras que, diferentemente, são momentos participativos. Isto é, os processos participativos constroem-se cotidianamente e são resultado da interação entre seus protagonistas. Opostamente os momentos participativos resultam de um espaço temporal determinado e concedido que poderá servir, apenas, para consultar e recolher opiniões ou sugestões de propostas. (OLIVEIRA, 2012, p. 86)

A PEEA, ao citar como princípio básico da EA "o enforque humanista, holístico, democrático e participativo” (SERGIPE, 2010, p. 3, grifo nosso), revela a preocupação por uma participação como atuação democrática, principalmente no que diz respeito à EA na construção de conhecimentos que contribuam na busca por uma sociedade mais sustentável. 
Em outro momento, na mesma política, a democracia é apontada como proposta de socialização de informações.

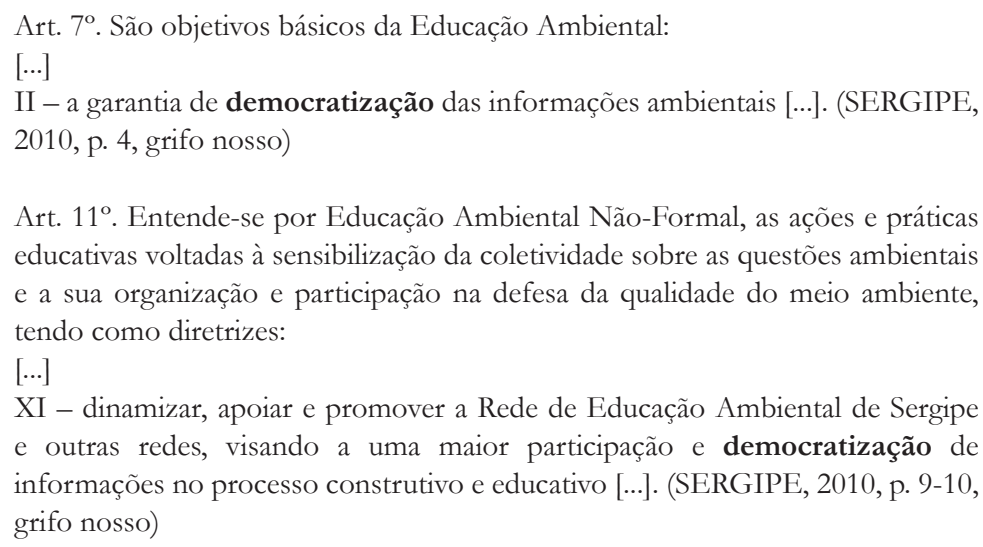
educativas voltadas à sensibilização da coletividade sobre as questões ambientais e a sua organização e participação na defesa da qualidade do meio ambiente, tendo como diretrizes:

$[\cdots]$

XI - dinamizar, apoiar e promover a Rede de Educação Ambiental de Sergipe e outras redes, visando a uma maior participação e democratização de informações no processo construtivo e educativo [...]. (SERGIPE, 2010, p. 9-10, grifo nosso)

Nesse sentido, Machado (1991) sublinha que o acesso à informação deve ser entendido como um importante componente integrante da democracia ambiental a fim de dotar a sociedade em geral e as camadas populares em particular de instrumentos para o exercício da cidadania. Senão, cai-se em uma democracia fictícia. Assim, Pastuk (1993) entende que cabe à EA, de fato, contribuir para a participação pública, oferecendo informações à população afetada pelos riscos ambientais e dela colhendo-as, no sentido de poder entender e avaliar como e o quanto é afetada.

Há, ainda na PEEA, a perspectiva de democracia como cooperação, em busca de uma sociedade sustentável e justa.

\footnotetext{
Art. $7^{\circ}$. São objetivos básicos da Educação Ambiental:

$[\cdots]$

V- o estímulo à cooperação entre municípios, com vistas à construção de uma sociedade ambientalmente equilibrada, fundada nos princípios da liberdade, igualdade, solidariedade, democracia, justiça social, responsabilidade e sustentabilidade [...]. (SERGIPE, 2010, p. 4, grifo nosso)
}

A democracia com sentido de cooperação, dicotomizada da competição por interesses particulares, pode deslocar o problema para a amenização dos conflitos, eliminando sua problematização e desconsiderando a disputa por espaços de poder que podem ser delineados entre grupos organizados da sociedade. Embora diversos estudos empíricos sobre tais esferas de participação apontem para os conflitos desenvolvidos no interior do processo de interação - seja entre população e governo, seja entre diferentes segmentos sociais -, o 
discurso que se apresenta é o da cooperação romantizada como caminho para o aperfeiçoamento da democracia, não obstante o dissenso seja um dos pilares da sociedade democrática (GRAMSCI, 2004).

Todavia, esse processo de institucionalização da EA, em especial da participação como caminho democrático, tem ocorrido, muitas vezes, de forma "meandrosa" (CUNHA, 2007). A participação se apresenta na maioria das políticas públicas como mais uma forma de consenso. Assim, como afirma Montaño (p. 45, 2008), no sentido defendido nas políticas públicas, "não há, neste conceito, lutas de classes, não há sequer lutas sociais, não há contradições econômicas, sequer há contradições políticas; há consensos". Tal fato se revela principalmente quando as lutas são anunciadas como participação coletiva nas políticas.

Ademais, é preciso avançar e potencializar políticas, campos e espaços de discussões, tendo em vista que, apesar dos debates nacionais e da implementação de políticas públicas, a EA, sobretudo em sua dimensão participativa, ainda não está presente, em seu sentido pleno de ato político e de exercício da cidadania, no processo educativo e democrático. Quando está, encontra-se fragilizada, pois é realizada de forma transitória, romântica e conservadora, conforme denunciado nas pesquisas do campo citadas anteriormente (OLIVEIRA, 2012).

É indubitável a importância da discussão sobre participação e democracia na implementação da EA Crítica no atual contexto de crise socioambiental. Entretanto, esse tipo de discussão precisa envolver os(as) professores(as)/ educadores(as), para que possam constantemente refletir sobre sua práxis.

\section{CONSIDERAÇÕES FINAIS}

No texto oficial e no percurso de construção da política sergipana de EA, foi possível identificar as concepções de participação, cidadania, democracia e currículo, verificando as demandas atuais para a EA nas unidades escolares sergipanas, advindas da SEED e dos(as) professores(as) envolvidos(as) diretamente com essas ações nas escolas. O objetivo maior dessa análise foi refletir sobre as dificuldades, os desafios e as possibilidades para a implementação da Lei n. ${ }^{\circ}$ 6.882/10 na educação formal em Sergipe e para o apontamento das diretrizes futuras e necessárias afinadas à EA Crítica, as quais ainda precisam ser alcançadas.

Há muito a avançar na prática pedagógica de EA em Sergipe. Por meio de políticas públicas, planos, programas e projetos de governo para uma educação verdadeiramente política, participativa e emancipatória, de enfrentamento da crise socioambiental, é possível que a EA Crítica integre oficial e metodologicamente o processo educativo. Ademais, iniciativas individuais e pontuais de mudança são 
desestabilizadas, caso não incorporem em seu escopo o ambiente mais amplo; e enfraquecidas em seus ideais, caso seus esforços não ressoem nas tantas outras forças que compõem o molde daquilo que se deseja transformado.

No caso sergipano, para que isso aconteça, a PEEA precisa ser efetivamente implementada, o que requer sua regulamentação oficial mediante publicação de decreto de lei, de forma que, em conjunto, envolvendo os municípios, possa cumprir o dever fundamental de difundir a EA na educação formal. Posteriormente, em um movimento participativo de embate contrahegemônico, a sociedade e os(as) gestores(as) políticos poderão concretizar o marco regulatório estadual da Lei n. ${ }^{\circ}$ 6.882/10 com a criação de um Programa e de um Plano Estadual de Educação Ambiental e de um programa especificamente para a formação em EA que envolva docentes e, sobretudo, gestores(as) com cargos administrativos na SEED e/ou nas escolas, instrumentalizando-os(as) para atuar na sociedade como futuros intelectuais orgânicos. Claro que deve haver cuidado para evitar amontoamentos de cursos de formação sem reflexão e repercussão na prática pedagógica.

$\mathrm{Na}$ busca por entender e mapear, com fidedignidade - reconhecido o risco desse tipo de processo -, as concepções e os sentidos revelados por meio dos instrumentos de produção de dados utilizados durante a investigação, tornou-se possível elencar e delimitar conceitualmente as categorias a priori de participação, cidadania e democracia. No momento de reconhecer as categorias durante a triangulação dos dados, aquelas que prevaleceram foram as concepções reducionistas e hegemônicas. Repensar a EA é repensar a educação, ou seja, tratase de transformar os padrões conservadores, individualizantes e antropocêntricos da lógica mercadológica vigente. É indubitável a importância da discussão sobre políticas públicas ambientais e sobre seu potencial na implementação da EA Crítica no atual contexto de crise socioambiental. Nessa direção, esse tipo de discussão precisa envolver os(as) professores(as)/educadores(as) e os(as) gestores(as) políticos(as), para que possam refletir constantemente sobre sua práxis e buscar ações transformadoras e revolucionárias.

\section{REFERÊNCIAS}

ADORNO, T. W. Educação e emancipação. Rio de Janeiro: Paz e Terra, 2006.

AVRITZER, L. Globalização e espaços públicos: a não regulação como estratégia de hegemonia global. Revista Crítica de Ciências Sociais, Coimbra, CES, n. 63, p. 107-121, 2002. 
BACKER, J. I. L. The right to participation in environmental matters. In: CONFERENNCIA INTERNACIONAL DE DIREITO AMBIENTAL, 1, 1991, Rio de Janeiro. Anais... Rio de Janeiro: Prefeitura da Cidade, 1991. p. 267-280.

BRANDÃO, C. R. Soletrar a letra P: povo, popular, partido e política. In: FÁVERO, G.; SEMERARO, G. (Orgs.). Democracia e construção do público no pensamento educacional. Petrópolis, RJ: Vozes, 2002. p. 105-145.

BRASIL. Lei n. ${ }^{\circ}$ 6.938, de 31 de agosto de 1981. Dispõe sobre a Política Nacional do Meio Ambiente, seus fins e mecanismos de formulação e aplicação e dá outras providências. Diário Oficial da União, Brasília, DF, 2 set. 1981.

Constituição Federal de 1988. Constituição [da] República Federativa do Brasil. Brasilia, DF: Senado Federal 1988.

Lei n. ${ }^{\circ}$ 9.394, de 20 de dezembro de 1996. Estabelece as diretrizes e bases da educação nacional. Diário Oficial da União, Brasília, DF, 20 dez. 1996.

Lei n. ${ }^{\circ}$ 9.795, de 27 de abril de 1999. Dispõe sobre Educação Ambiental e institui a Política Nacional de Educação Ambiental, e dá outras providências. Diário Oficial da União, Brasília, DF, 28 abr. 1999.

. Lei n. ${ }^{\circ}$ 10.172, de 9 de janeiro de 2001. Aprova o Plano Nacional de Educação e dá outras providencias. Diário Oficial da União, Brasília, DF, 10 jan. 2001.

- Ministério do Meio Ambiente; Ministério da Educação. Programa Nacional de Educação Ambiental (ProNEA). 3. ed. Brasília: Edições MMA, 2005.

CERQUIER-MANZINI. M. L. O que é cidadania. 4. ed. São Paulo: Brasiliense, 2010.

CUNHA, L. A. O desenvolvimento meandroso da educação brasileira entre o Estado e o mercado. Educação e Sociedade, Campinas, v. 28, n. 100, p. 809-829, out. 2007. 
DAGNINO, E. Sociedade civil, participação e cidadania: de que estamos falando? In: MATO, D. (Org.). Políticas de ciudadanía y sociedad civil en tiempos de globalización. Caracas: FACES; Universidad Central de Venezuela, 2004. p. 95-110.

DEMO, P. Participação é conquista: noções de política social. 6. ed. São Paulo, Cortez, 2009.

GADOTTI, M. Boniteza de um sonho: ensinar-e-aprender com sentido. São Paulo: Instituto Paulo Freire, 2008.

GIDDENS, A. O mundo na era da globalização. 3. ed. Lisboa: Editorial Presença, 2001.

GRAMSCI, A. Cadernos do cárcere. Rio de Janeiro: Civilização Brasileira, 2004. v. 1-2.

GUIMARÃES, M. Educação ambiental: no consenso um embate? São Paulo: Papirus. 2000.

. A formação de educadores ambientais. São Paulo: Papirus, 2004.

HELD, D. Modelos de democracia. Belo Horizonte: Paidéia, 1994.

LOUREIRO, C. F. B. Teoria crítica. In: FERRARO-JÚNIOR, L. A. (Org.). Encontros e caminhos: formação de educadores ambientais e coletivos jovens. Brasília: MMA, Diretoria de Educação Ambiental, 2005. p. 225-232

- Teoria social e a questão ambiental: pressupostos para uma práxis crítica em educação ambiental. In: ___ _ _ LAYRARGUES, P. P.; CASTRO, R. S. (Orgs.). Sociedade e meio ambiente: a educação ambiental em debate. 5. ed. São Paulo: Cortez, 2008. p. 12-51.

. Educação ambiental e movimentos sociais na construção da cidadania ecológica e planetária. In: ___ _ _ LAYRARGUES, P. P.; CASTRO, R. S. de (Orgs.). Educação ambiental: repensando o espaço da cidadania. 5. ed. São Paulo: Cortez, 2011. p. 73-103. 
MACHADO, P. A. L. Direito à informação ambiental e sociedade civil. In: CONFERÊNCIA INTERNACIONAL DE DIREITO AMBIENTAL, 1, 1991, Rio de Janeiro. Anais... Rio de Janeiro: Prefeitura da Cidade, 1991. p. 281-285.

MARSHALL, T. H. Cidadania, classe social e status. Rio de Janeiro: Zahar, 1967.

MEDINA, N. M. Breve histórico da educação ambiental. In: PÁDUA, S. M.; TA- BANEZ, M. F. (Orgs.). Educação ambiental: caminhos trilhados no Brasil. Brasília, DF: IPE, 1997. p. 257-269.

MÉSZÁROS, I. Para além do capital. São Paulo: Boitempo Editorial; Campinas: Editora da UNICAMP, 2002.

MINAYO, M. C. de S. Ciência, técnica e arte: o desafio da pesquisa social. In: . et al (Orgs.). Pesquisa social: teoria, método e criatividade. 2. ed. Petrópolis: Vozes, 1994. p. 9-29.

MONTAÑO, C. Política social e participação societária. Sociedade em Debate, Pelotas, n. 38, v. 14 (1), p. 37-46, jan./jun. 2008.

MORAES, R. Uma tempestade de luz: a compreensão possibilitada pela análise textual discursiva. Ciência e Educação, Bauru - SP, v. 9, n. 2, p. 191-211, 2003.

.; GALIAZZI, M. do C. Análise textual discursiva: processo reconstrutivo de múltiplas faces. Ciência e Educação, Bauru - SP, v. 12, n. 1, p. 117-128, 2006.

OLIVEIRA, A. L. A perspectiva participativa para a inserção da educação ambiental crítica em escolas da Baixada Fluminense. 2012. 143 f. Dissertação (Mestrado em Educação) - Instituto de Educação/Instituto Multidisciplinar, Universidade Federal Rural do Rio de Janeiro, Seropédica/Nova Iguaçu, 2012.

PASTUK, M. Estado de participação pública em questões ambientais urbanas. 1993. 116 f. Dissertação (Mestrado em Educação) - Instituto de Estudos Avançados em Educação, Fundação Getúlio Vargas, Rio de Janeiro, 1993.

REIGOTA, M. A. S. Educação ambiental: fragmentos de sua história no Brasil. In: NOAL, F;; REIGOTA, M. (Orgs.). Tendências da educação ambiental brasileira. Santa Cruz do Sul: Edunisc, 1998. p. 229-258. 
RODRIGUES, N. Educação: da formação humana à construção do sujeito ético. Educação e Sociedade, Campinas, v. 22, n. 76, p. 232-257, 2001.

SANTOS, B. S. A crítica da governação neoliberal: o Fórum Social Mundial como política e legalidade cosmopolita subalterna. Revista Crítica de Ciências Sociais, Coimbra, v. 72, p. 7-44, 2005.

SERGIPE. Lei n. ${ }^{\circ}$ 6.882, de 8 de abril de 2010. Institui a Política Estadual de Educação Ambiental. Diário Oficial de Sergipe, Aracaju, SE, 2010.

SORRENTINO, M.; TRAJBER, R.; MENDONÇA, P.; JUNIOR, L. A. F. Educação ambiental como política pública. Educação e Pesquisa, São Paulo, v. 31, n. 2, p. 285-299, 2005.

TRAJBER, R.; MENDONÇA, P. R. (Orgs.). Educação na diversidade: o que fazem as escolas que dizem que fazem educação ambiental? Brasilia: Secretaria de Educação Continuada, Alfabetização e Diversidade; MEC; UNESCO, 2006.

ALINE LIMA DE OLIVEIRA NEPOMUCENO é Doutora em Educação (PPGEDUFS), mestre em Educação (PPGEduc-UFRRJ-2012), graduação em Ciências Biológicas (Licenciatura Plena) (UFS- 2009). Desepenha pesquisas junto ao Grupo de Estudos e Pesquisa em Educação Ambiental de Sergipe (GEPEASEUFS), ao Projeto Sala Verde na UFS, ao Grupo de Estudos e Pesquisa em Educação Ambiental, Diversidade e Sustentabilidade (GEPEADS-UFRRJ) e ao Grupo de Estudos em Educação Científica (GEPEC-UFS), atuando nas áreas de Educação Ambiental, Formação de Professores, Metodologias Participativas, Metodologias para o Ensino de Ciências e Biologia. É professora do ensino superior efetiva do Departamento de Biologia da UFS, nas disciplinas de Metodologias para o Ensino de Ciências e Biologia e membro permanente do Programa de Pós-gradação em Educação (PPGED) - UFS.

E-mail: aline_limadeoliveira@yahoo.com.br

ORCID: http://orcid.org/0000-0001-7936-2167

MARIA INÊZ OLIVEIRA ARAUJO é licenciada em Ciências Biológicas pela Universidade Federal de Sergipe (1981), mestrado em Educação pela Universidade Federal de Sergipe (1996), doutorado em Educação pela Universidade de São Paulo (2004) e pós-doutora pela Universidade do Porto, com bolsa da CAPES. Professora Titular da Universidade Federal de Sergipe, desenvolvendo suas atividades acadêmicas de graduação no curso de Pedagogia, no Curso Licenciatura em Ciências Biológicas, orientando monografia; professora do Programa de Pós-Graduação em Educação como professora da disciplina Pesquisa em Educação e orientadora do mestrado e doutorado. Líder do Grupo de Estudos e Pesquisa de Educação Ambiental do estado de Sergipe 
- GEPEASE e pesquisadora da Sala Verde na UFS. .Tem experiência na área de Educação, com ênfase em Educação Ambiental, ensino de Ciências e Biologia, metodologia e formação de professores. Professora Titular aposentada, com vínculo de professora voluntária no Programa de Pós-Graduação em Educação da Universidade Federal de Sergipe.

E-mail: inezaraujo58@gmail.com

ORCID: http://orcid.org/0000-0002-0115-0049

Recebido em junho de 2019

Aprovado em setembro de 2019 